\title{
ESTABILIDAD Y GARANTÍAS DE LOS DERECHOS LABORALES DE LOS FUNCIONARIOS Y EMPLEADOS DEL SECTOR JUDICIAL EN COLOMBIA*
}

\author{
Margarita Almario Pantoja \\ Universidad Católica de Colombia
}

\begin{abstract}
Resumen
Mediante el presente artículo se pretende exponer la situación laboral de los funcionarios y empleados del sector judicial en un contexto social, político y económico, dentro de las posturas del nuevo derecho constitucional. La función de administrar justicia en las últimas décadas ha generado grandes debates internacionales, nacionales y locales; asimismo, la globalización y la lucha de los funcionarios judiciales por la protección de sus derechos laborales -dada por la evasión y omisión del Gobierno frente a estos temas- han desembocado en estudios académicos de toda índole, en los que se ha procurado establecer la importancia de la Rama Judicial y las garantías laborales de estos funcionarios. Desde la concepción de los nuevos Estados constitucionales, la función del juez tiene importancia como sujeto social con características específicas.
\end{abstract}

Palabras clave: derechos humanos, Derecho Laboral, Derecho Constitucional.

La autora: abogada. Exfuncionaria judicial de los juzgados laborales de descongestión del circuito de Cali. Correo electrónico: marga.almapanatoja@gmail.com

Recibido: 3 de mayo de 2016; evaluado: 15 de mayo de 2016; aceptado: 23 de mayo de 2016.

Este artículo es producto del primer capítulo de la tesis para optar el título de magíster en Derecho Constitucional, titulada "Estabilidad de los funcionarios y empleados del sector judicial colombiano: perspectiva constitucional". 


\title{
STABILITY AND GUARANTEES OF LABOR RIGHTS OF OFFICIALS AND EMPLOYEES OF THE JUDICIAL BRANCH IN COLOMBIA
}

\author{
Margarita Almario Pantoja \\ Universidad Católica de Colombia
}

\begin{abstract}
This article aims to explain the labor status of officials and employees of the judicial branch in a social, political, and economic context, within the provisions of the new constitutional law. The task of administering justice in recent decades has generated major international, national, and local debates. Similarly, globalization and the struggle of judicial officers to protect their labor rights—given the evasive attitude and neglect of the Government regarding these topics—have resulted in all kinds of academic studies, seeking to establish the importance of the judicial branch and labor guarantees of judicial officials. Since the beginning of the new constitutional states, the role of the judge as a social subject with specific characteristics has been of great importance.
\end{abstract}

Keywords: Human Rights, Labor Law, Constitutional Law.

About the author: Lawyer. Ex Judicial Officer of the overflow labor courts at the circuit of Cali. Email: marga.almapanatoja@gmail.com

Received: May 3, 2016; reviewed: May 15, 2016; accepted: May 23, 2016. 


\section{Administración de justicia y Estado neoconstitucional}

La administración de justicia dentro de la estructura estatal se ha caracterizado por ser el soporte especializado del saber jurídico. En el contexto colombiano, la función que cumple la organización judicial es compleja, debido a situaciones políticas de corrupción, tensiones por el poder central, presencia del narcotráfico y conflicto armado, entre otras situaciones que determinan la dificultad de aplicar justicia:

[... la coyuntura institucional actual del país plantea importantes retos para la justicia: de un lado los jueces han adquirido un protagonismo insospechado en la definición de los principales problemas institucionales. La crisis de la representación política y la corrupción han ocasionado una especie de intervención excepcional de los jueces en asuntos que inicialmente no les correspondían. De otro lado, la incapacidad creciente de la justicia para responder a las demandas de seguridad que se originan en la acción de las organizaciones armadas, pone de presente una crisis profunda en el funcionamiento de la justicia. Protagonismo político y deficiencias funcionales se encuentran necesariamente conectados: mientras la justicia no resuelva sus problemas funcionales y adquiera fortaleza y capacidad mediante el logro de sus compromisos sociales naturales, su intervención en los grandes debates políticos puede ser el pretexto para una desviación de objetivos y para un debilitamiento aún mayor de sus cometidos [...]. Para reconstruir las instituciones se requiere de la participación de otros organismos del Estado, y particularmente de los jueces. ${ }^{1}$

La organización judicial ha tenido transformaciones en las últimas décadas en el país. Estos cambios son resultado del saber jurídico de los empleados y funcionarios judiciales que se ha consolidado por los estudios superiores y las actualizaciones académicas que adelantan de forma particular y con sus propios recursos, puesto que la institución no los financia. Ante el fenómeno de la globalización, que innova el saber jurídico y la práctica, los funcionarios y empleados judiciales tienen como prioridad su actualización académica, pese a la escasez de instituciones públicas encargadas de capacitarlos.

La formación avanzada para el desempeño de habilidades particulares propias de determinadas ocupaciones no es común; predomina la educación profesio-

Mauricio García Villegas, "Introducción" en Jueces sin Estado. La justicia colombiana en zonas de conflicto armado, dir. Mauricio García Villegas (Bogotá: Siglo del hombre editores, 2008), 16-17. 
nal por áreas de conocimiento, con la excepción de la ocupación judicial, en donde se han desarrollado algunos programas de capacitación. La ocupación judicial no había contado con programas académicos diseñados para absolver las necesidades específicas que corresponden al desempeño de sus atribuciones particulares. Por años la entidad de capacitación, adscrita al Ministerio de Justicia, se limitó a reproducir los esquemas de formación en derecho positivo de las universidades, ya fuera contratando con ellas los cursos respectivos a sus profesores. Este esquema no ha desaparecido, pero en época reciente el Consejo Superior de la Judicatura, sobre un diseño muy general, contrata con universidades cursos cortos y semipresenciales que comprenden nociones generales de administración, derechos fundamentales, formas de resolución de conflictos, filosofía del derecho, sociología de la justicia. Ellos constituyen el embrión, aún incipiente, de cursos especializados para jueces. Sin embargo, no hay un proceso general de formación temática para acceder a conocimientos ocupacionales singulares, en particular por limitaciones presupuestales, ni un ambiente propicio para la socialización en los roles judiciales. Sobre esa base no puede afirmarse que la formación actual de la judicatura sea un factor especial que coadyuve a la desintegración de la unidad profesional. ${ }^{2}$

Pese a estas actualizaciones académicas en la Ciencia Jurídica, que son particulares y esporádicamente institucionales, la administración de justicia recibe críticas por parte de los mismos funcionarios, los académicos y la sociedad, debido a las decisiones que toman los jueces y sus funcionarios y que en varias ocasiones están en contravía de la justicia y a favor de intereses económicos y políticos:

En Colombia las relaciones entre política y justicia no son extrañas. Desde luego en el discurso contemporáneo prima una noción de separación entre política y derecho-justicia. Sin embargo, la historia se nutre de ejemplos en los cuales la administración de justicia se ha pronunciado en forma claramente política, a la vez, de distintos modos, los funcionarios judiciales han evidenciado sus preferencias en la materia. Por otro lado, hasta época más o menos reciente, el sistema normativo exigía a los jueces que declararan su filiación política como requisito de acceso al cargo, pues el sistema había establecido una regla de paridad política en los cargos públicos, entre el partido ganador y el segundo en los resultados electorales, lo que en la práctica significaba

Germán Silva García, El mundo real de los abogados y de la justicia. La profesión jurídica. Tomo I (Bogotá: Universidad Externado de Colombia, ILSA, 2001), 50-51. 
tener que definirse como liberal o conservador, dada la hegemonía de los dos partidos tradicionales que se alternaban el poder. ${ }^{3}$

La función de administrar justicia es la base fundamental del Estado constitucional. Si se administra justicia correctamente, hay una buena prestación del servicio, lo cual depende de varios factores: en primer lugar, las contraprestaciones a las que se tiene derecho por ofrecer un servicio público, lo que lleva consigo una serie de derechos laborales adquiridos; en segundo lugar, las instalaciones en donde se va a prestar el servicio tienen que ser adecuadas y contar con los implementos suficientes y necesarios y, por último, tienen que existir políticas eficaces tendientes a cubrir la alta demanda de la justicia. Entonces, debe existir una entidad que vele por el correcto funcionamiento de la administración de justicia, proteja los intereses de los usuarios y también los derechos de los servidores judiciales y se diseñe una efectiva y eficaz política de administración de justicia que actúe en armonía con las otras ramas del poder público.

El funcionamiento correcto del Poder Judicial depende en exclusiva del personal que presta sus servicios a la Rama Judicial. Los funcionarios y empleados judiciales son los encargados de materializar el acceso a la justicia, por lo que se convierten en la parte fundamental de la Rama; esto conlleva a cuestionarse acerca de sus derechos laborales, los cuales han sido protegidos por medio de tratados internacionales y por el ordenamiento jurídico. Resulta indispensable que los derechos laborales y constitucionales de los servidores judiciales se cumplan como se ha establecido internacional y jurisprudencialmente:

[...] el asunto de generar espacios para la participación de los jueces quedaba sujeto a la bondad del poder ejecutivo, que impulsaba el proyecto en el Congreso, el cual optó por la exclusión, reacio a la incómoda presencia de jueces sindicalizados. Dentro de un contexto economicista y concentrado en la preocupación por el status, con ausencia de debate de interés sobre los roles sociales y políticos del juez, y acerca de la relevancia de la estructura judicial para el rumbo de la sociedad como tendencias predominantes, no otro podía ser el resultado. ${ }^{4}$

3 Germán Silva García, El mundo real de los abogados y de la justicia. Administración de justicia. Tomo III (Bogotá: Universidad Externado de Colombia, ILSA, 2001), 219-220.

4 Silva García, El mundo real de los abogados y de la justicia. Administración de justicia. Tomo III, 188. 
El avance constitucional llevado a cabo en Bolivia, Ecuador, Venezuela y Colombia ha tenido incidencia en las nuevas teorías constitucionales, lo que ha generado el cambio contextual y social de las políticas de Estado. Esto podría entenderse como una utopía, puesto que hoy por hoy los Estados no materializan las nuevas teorías surgidas del constitucionalismo; la actividad de la Rama Judicial dentro de la estructura estatal se ha politizado y cada día va perdiendo imparcialidad. Es evidente el mal manejo que se ha hecho de este órgano del poder público por parte del poder central, lo cual ha generado la mal llamada "crisis de la justicia":

En América Latina el desarrollo de las asociaciones judiciales con un tono político, reconociéndole ese sentido a la actividad judicial y relacionando su práctica con el desarrollo avanzado de la democracia que permita, a la vez superar el estrecho marco de las reivindicaciones estamentales, es todavía muy limitado [...]. Otros elementos puntuales han sido citados como relevantes en el desarrollo asociativo democrático. Existe un consenso sobre el impacto de la formación de los jueces, en lo que concierne a la definición de sus roles, punto de importancia capital, muy por encima de la preparación técnica. Esta cuestión sitúa a su vez en primer plano las tareas desempeñadas en este campo por las escuelas judiciales, normalmente administradas por consejos de las magistraturas. En Alemania el modelo desarrollado en Bremen marca la diferencia entre la educación universitaria tradicional y una formación práctica, que refleja la evolución histórica, social y económica del derecho. En Francia apunta Pierre Mounier, la Escuela de la Magistratura se constituye en un espacio de encuentro que facilita la discusión común sobre la justicia en una reflexión colectiva. ${ }^{5}$

\section{Evaluación del cumplimiento del derecho a la estabilidad laboral de los funcionarios y empleados del sector judicial desde la protección de derechos fundamentales}

La concepción de Constitución dentro de la estructura estatal está investida de relevancia, ya que es la base fundamental de los Estados modernos. Esto implica que las nuevas teorías constitucionales acojan los postulados internacionales que influyen directamente en la Rama Judicial. Los nuevos conceptos constitucionales le imponen al juez hacer una interpretación más allá de lo establecido en la ley y es

Silva García, El mundo real de los abogados y de la justicia. Administración de justicia. Tomo III, 162, 164. 
por esta razón que el Poder Judicial es parte fundamental dentro del organigrama estatal; es una labor que implica no solo la protección de derechos fundamentales, sino la protección del texto constitucional, que consiste en conservar su núcleo y proteger su esencia por encima de la legislación interna:

A través de las múltiples transformaciones que ha sufrido, la noción de Constitución ha conservado un núcleo permanente: la idea de un principio supremo que determina por entero el orden estatal y la esencia de la comunidad constituida por ese orden. Como quiera que se defina, la Constitución es siempre el fundamento del Estado, la base del orden jurídico que pretende conocerse. Lo que se entiende siempre y ante todo por Constitución y la noción coincide en este sentido con la forma de Estado es que la Constitución constituye un principio donde se expresa jurídicamente el equilibrio de fuerzas políticas en un momento determinado, es la norma que regula la elaboración de las leyes, de las normas generales en ejecución de las cuales se ejerce la actividad de los órganos estatales, tribunales y autoridades administrativas. Esta regla de creación de las normas jurídicas esenciales del Estado, de determinación de los órganos y del procedimiento de la legislación, forma la Constitución en sentido propio, originario y estricto del término. La Constitución es la base indispensable de las normas jurídicas que regulan la conducta recíproca de los miembros de la colectividad estatal, así como de aquellas que determinan los órganos necesarios para aplicarlas e imponerlas y la forma como estos órganos habían de proceder; es decir, la Constitución es, en suma, el asiento fundamental del orden estatal. ${ }^{6}$

El papel del juez ha cambiado con la llegada de las nuevas teorías constitucionales: ya no es un juez positivista, sino uno garantista que tiene una concepción más amplia y menos conservadora de las teorías del Derecho. La aplicación de esas nuevas teorías implica el sometimiento a la academia, al estudio juicioso y con responsabilidad de las trasformaciones jurídicas, lo que permite que haya un acercamiento más prolongado a las necesidades sociales:

En efecto, la sujeción del juez a la ley ya no es, como en el viejo paradigma positivista, sujeción a la letra de la ley, cualquiera que fuere su significado, sino sujeción a la ley en cuanto válida, es decir, coherente con la Constitución. Y en el modelo constitucional garantista la validez ya no es un dogma asociado a

6 Hans Kelsen, La garantía jurisdiccional de la Constitución. La justicia constitucional (México D. F.: Instituto de investigaciones jurídicas, 2001), 20-21. 
la mera existencia formal de la ley, sino una cualidad contingente de la misma ligada a la coherencia de sus significados con la Constitución, coherencia más o menos opinable y siempre remitida a la valoración del juez. De ello se sigue que la interpretación judicial de la ley es también siempre un juicio sobre la ley misma, que corresponde al juez junto con la responsabilidad de elegir los únicos significados válidos, o sea, compatibles con las normas constitucionales sustanciales y con los derechos fundamentales establecidos por las mismas. ${ }^{7}$

En el texto constitucional se encuentra gran variedad de derechos, así como también la estructura del Estado y el manual de funcionamiento de las corporaciones públicas y las entidades pertenecientes al sector centralizado y descentralizado. El catálogo de derechos protegidos constitucionalmente se ha dividido entre los que son fundamentales y los que son de otra índole, como los derechos sociales. Es importante tener presente la definición de derecho fundamental:

[...] son derechos fundamentales todos aquellos derechos subjetivos que corresponden universalmente a todos los seres humanos en cuanto dotados del status de personas, de ciudadanos o personas con capacidad de obrar; entendiendo por derecho subjetivo cualquier expectativa positiva (de prestaciones) o negativa (de no sufrir lesiones) adscrita a un sujeto por una norma jurídica; y por "status" la condición de un sujeto, prevista asimismo por una norma jurídica positiva, como presupuesto de su idoneidad para ser titular de situaciones jurídicas y/o autor de los actos que son ejercicio de éstas. ${ }^{8}$

En las teorías aplicables en el marco del nuevo constitucionalismo latinoamericano, los derechos fundamentales ya no se limitan al Legislador, pues el papel fundamental en el reconocimiento lo tiene el juez y es él quien dice cuáles son derechos fundamentales y cuáles no. Cabe señalar que las nuevas Constituciones incorporan varios derechos fundamentales al sistema jurídico y otros han sido reconocidos con base en interpretaciones jurídicas llevadas a cabo por funcionarios judiciales dentro de su función esencial como jueces de tutela, investidos de amplias facultades constitucionales en función de proteger la vulnerabilidad de los derechos primordiales. La función de la protección de derechos constitucionales implica una infracción:

Luigi Ferrajoli, Derechos y garantías. La Ley del más débil (Madrid: Trotta, 2004), 26.

Ferrajoli, Derechos y garantías, 37. 
Los derechos a protección son derechos constitucionales que ostenta su titular contra el Estado, es decir, a que éste le proteja de la interferencia de terceros. Los derechos a protección pueden tener una variedad de objetos. El espectro se extiende desde el homicidio o la calumnia hasta la protección ante los peligros asociados al uso pacífico de la energía nuclear. La principal fuente de problemas con que se topan los derechos a protección es que la protección de una parte significa la interferencia de otra. La protección ante comentarios despectivos presupone una interferencia con la libertad de expresión. Esta dialéctica de protección e interferencia da lugar a la siguiente observación: sólo puede haber una solución correcta si ambos derechos, el de protección y el de defensa, han de ser optimizados de acuerdo con las normas de la proporcionalidad. Esta única solución correcta sería algo así como un punto ideal y supremo. ${ }^{9}$

La Corte Constitucional ha definido el alcance del concepto de derecho fundamental. Para ello, reunió los conceptos que surgieron de la Asamblea Nacional Constituyente de 1991 y llegó a la conclusión de que los derechos fundamentales no necesariamente son los que se encuentran expresos en el texto constitucional, sino que el juez puede decidir cuándo un derecho adquiere la calidad de fundamental. Asimismo, la Corte deja claro que los derechos fundamentales no pueden ser el resultado de debates políticos como es el caso de las leyes, dado su contenido esencial:

Para que un derecho constitucional pueda ser considerado como fundamental, debe además ser el resultado de una aplicación directa del texto constitucional, sin que sea necesario una intermediación normativa; debe haber una delimitación precisa de los deberes positivos o negativos a partir del solo texto constitucional. Por lo tanto, en normas que poseen una "textura abierta", como por ejemplo las que establecen meros valores constitucionales, a partir de la cual el legislador entra a fijar el sentido del texto, no podría presentarse la garantía de la tutela. Está claro que no puede ser fundamental un derecho cuya eficacia depende de decisiones políticas eventuales. Ahora bien, la eficacia directa no se reduce a los derechos de aplicación inmediata o a los derechos humanos de la llamada primera generación. En algunos casos los derechos económicos, sociales y culturales pueden ser objeto de protección especial por medio de la tutela; tal es el caso del artículo 50 sobre los derechos de los niños; los derechos consagrados en el inciso segundo del artículo 53 sobre principios mínimos

9 Robert Alexy, Derechos sociales y ponderación (Madrid: Fundación Coloquio Jurídico Europeo, 2009), 52. 
fundamentales de los trabajadores; el derecho establecido en el artículo 73 sobre obtención de información contenida en documentos públicos. ${ }^{10}$

En medio de los debates que han surgido alrededor del concepto de derecho fundamental, se resalta que, a pesar de la variada jurisprudencia que existe sobre derechos fundamentales, la Corte no ha encontrado consenso en las providencias para definir lo que es y lo que no es fundamental. Es relevante la competencia de interpretación constitucional que la Corte otorga al juez de tutela como garante de la protección de derechos constitucionales de primera índole y su papel proteccionista frente al sujeto afectado.

La Corte ha sido clara al establecer la competencia del juez respecto al reconocimiento de derechos fundamentales, ya que no debe limitarse a lo que está expresamente reconocido en el texto constitucional, sino que tiene la competencia de asignar la categoría de derecho fundamental a otra clase de derecho que esté reconocido por la Constitución, como es el caso del Artículo 53 que, a pesar de que no está en la categoría de fundamental, ha adquirido tal característica mediante los fallos de tutela.

El derecho a la estabilidad laboral se encuentra protegido dentro del ordenamiento constitucional colombiano específicamente en el artículo 53 de la Constitución el cual establece que:

El Congreso expedirá el estatuto del trabajo. La ley correspondiente tendrá en cuenta por lo menos los siguientes principios mínimos fundamentales: igualdad de oportunidades para los trabajadores; remuneración mínima vital y móvil, proporcional a la cantidad y calidad de trabajo; estabilidad en el empleo; irrenunciabilidad a los beneficios mínimos establecidos en normas laborales; facultades para transigir y conciliar sobre derechos inciertos y discutibles; situación más favorable al trabajador en caso de duda en la aplicación e interpretación de las fuentes formales de Derecho; primacía de la realidad sobre formalidades establecidas por los sujetos de las relaciones laborales; garantía a la seguridad social, la capacitación, el adiestramiento y el descanso necesario; protección especial a la mujer, a la maternidad y al trabajador menor de edad.

La protección de derechos laborales es importante dentro de las políticas públicas establecidas por los Estados, lo cual incide en el cumplimiento de la legislación

10 Corte Constitucional, Sentencia T-406 de 5 de junio de 1992, M. P. Ciro Angarita Barón. 
interna existente y genera políticas laborales eficientes. El trabajo decente, como lo ha calificado la OIT, implica el desarrollo de actividades laborales en condiciones dignas. El Estado de Derecho procura el sometimiento a las normas existentes y el cumplimiento de las mismas, es decir, tendría que "sobreproteger" las normas laborales. La protección interna de normas laborales ha sido muy precaria, pues no se ha procurado innovar la legislación y no se hacen políticas eficientes que mejoren las condiciones laborales tanto en el sector privado como en el público:

El incumplimiento de la legislación ha tenido efectos sumamente importantes en la determinación de los modelos o sistemas de las relaciones de trabajo, al poner en cuestión todo el andamiaje de derechos fundamentales, derechos individuales y derechos colectivos. Influye decisivamente en la cultura de cumplimiento pues su inobservancia no ocasiona mayores costos, e incluso puede significar un ahorro en países con tasas de inflación significativas. A esto debe añadirse que a partir de los años ochenta hubo un fuerte deterioro del interés por hacer efectiva esa intervención y las capacidades de fiscalización donde existían, provocando más segmentación de los mercados de trabajo. La falta de fiscalización y las dificultades de acceso a la justicia han contribuido a la flexibilización de las relaciones laborales, probablemente en mayor medida que algunas reformas legales, y se justifican en el temor a la destrucción de empleos que podría provocar una aplicación estricta de la legislación. Advirtiendo este problema, ya vigente desde siempre en las relaciones de trabajo en América Latina, pero agravado a partir de la década de los ochenta, los constituyentes latinoamericanos de la OIT en el año 2006 decidieron en forma tripartita que una de sus prioridades en la región sería el respeto y el cumplimiento efectivo de las normas sobre derechos laborales y, muy especialmente, sobre los principios y derechos fundamentales en el trabajo, como parte del esfuerzo para lograr que todas las mujeres y los hombres puedan acceder a un trabajo decente. El trabajo decente, como lo ha definido la OIT, consiste en mejorar las oportunidades que deben tener todos para conseguir un empleo productivo en condiciones de libertad, equidad, seguridad y dignidad humana. ${ }^{11}$

11 Adolfo Ciudad Reynaud, "La modernización de la justicia laboral en América Latina", Revista de Derecho Procesal, núm. 3-4 (2010): 293. 


\section{Derechos laborales de los funcionarios y empleados judiciales en Colombia dentro del Estado neoconstitucional}

La estructura judicial en el contexto colombiano se ha venido configurando paulatinamente. El mandato constitucional de organización del Estado y la división de poderes, las leyes y los decretos-ley han posibilitado esta organización. El Artículo 21 de la Ley Estatutaria de Administración de Justicia 270 de 1996 establece:

Artículo 21. Integración. La célula básica de la organización judicial es el juzgado, cualquiera que sea su categoría y especialidad y se integrará por el juez titular, el secretario, los asistentes que la especialidad demande y por el personal auxiliar calificado que determine el Consejo Superior de la Judicatura.

Esta organización ha llevado a que la estructura judicial presente un número responsable de empleados y funcionarios: "32 Tribunales Superiores y 3246 Despachos judiciales", ${ }^{12}$ según un estudio de la misma Rama Judicial. Por su parte, el Consejo Superior de la Judicatura determinó en un estudio: "23.501 servidores judiciales"; 13 esta cifra del Consejo Superior no tiene en cuenta a los funcionarios que prestan sus servicios a la Fiscalía General de la Nación, que se calcula son más de $18.000^{14}$ servidores según este ente investigativo, por lo que el total de funcionarios de la estructura judicial sería de 41.501 funcionarios.

En lo que respecta a las Altas Cortes, los magistrados que las integran son en total 76, de acuerdo con el Título III de la Ley 270 de 1996, el cual señala que "9 componen la Corte Constitucional; 23 la Corte Suprema de Justicia; 31 el Consejo de Estado y 13 el Consejo Superior de la judicatura". El Artículo 158 de la Ley 270 de 1996 indicó que "son funcionarios de carrera judicial los magistrados de los Tribunales y de las salas de los Consejos Seccionales de la Judicatura, jueces y empleados". El Consejo Superior de la Judicatura manifestó:

12 Rama Judicial, "Estructura y funciones de la administración de justicia", http://www.ramajudicial.gov.co/ documents/10228/1468683/estructura+y+funciones+de+la+administracion+de+la+justicia.pdf/d016a449f9c7-44ed-blfc-fbdac24b6575 (acceso noviembre 22, 2015), 19.

13 Consejo Superior de la Judicatura, "Plan sectorial de desarrollo de la Rama Judicial 2011-2014", https:// www.ramajudicial.gov.co/documents/10228/76250/Plan+Sectorial+2011+-+2014.pdf/9c2ad6f7-9ce8-45f8a281-0eb2751fle3d (acceso noviembre 25, 2015), 16.

14 Fiscalía General de la Nación. "Fiscalía General de la Nación". http://www.fiscalia.gov.co/colombia/wpcontent/uploads/2012/03/brochure_espanol.pdf (acceso agosto 30, 2015). 
[...] las convocatorias que se han llevado a cabo han permitido nombrar en propiedad a 594 Magistrados, 2.730 Jueces y 12.403 empleados [...] al año 2008 se adelantaron 62 convocatorias, 12 para funcionarios y 50 para empleados que abarcan la pluralidad de cargos del Sector Jurisdiccional de la Rama Judicial, en los que se han registrado 242.308 inscripciones de aspirantes para acceder a cargos de carrera que a su vez han dado lugar a cerca de 9.386 nombramientos por el sistema de méritos, a cargo de 4.524 autoridades nominadoras dentro de la administración de justicia. ${ }^{15}$

De acuerdo con los datos enunciados, la Rama Judicial tiene 15.727 servidores judiciales nombrados en propiedad y 7.774 nombrados en provisionalidad, para un total de 23.501 servidores judiciales, sin tener en cuenta a los funcionarios y empleados de descongestión judicial.

A pesar de que se han abierto convocatorias tendientes a cubrir las vacantes que existen en los despachos judiciales nacionales, esto no ha sido suficiente, ya que como se mencionó, hay 7.774 servidores judiciales en provisionalidad, nombramiento que no garantiza una estabilidad laboral en los cargos que ocupan dichos empleados judiciales. Esta cantidad tan significativa no debería presentarse en la Rama Judicial, debido a la función que tienen los servidores judiciales dentro de la estructura del poder judicial.

La Rama Judicial cuenta con el Plan Nacional de Descongestión, ordenado mediante el Artículo 63 de la Ley 270 de 1996:

Habrá un plan nacional de descongestión que será concertado con la Sala Administrativa del Consejo Superior de la Judicatura, según correspondiere. En dicho plan se definirán los objetivos, los indicadores de congestión, las estrategias, términos y los mecanismos de evaluación de la aplicación de las medidas.

Para que se materialicen las medidas de descongestión, se requiere crear juzgados, ya sean adjuntos o de descongestión, lo que conlleva nombramientos en provisionalidad; así, de acuerdo con el presidente de la Sala Administrativa del Consejo Superior de la Judicatura, Néstor Raúl Correa Henao, "en total existen 7.564 cargos

15 Consejo Superior de la Judicatura, "Plan sectorial de desarrollo de la Rama Judicial 2011-2014", 15, 35. 
de descongestión", ${ }^{16}$ es decir, para el 19 de diciembre de 2014, la estructura judicial contaba con un total nacional de 49.065 servidores judiciales entre funcionarios y empleados, incluidos aquellos de la Fiscalía General de la Nación. El panorama actual es otro, ya que debido a las políticas de presupuesto para el año 2015, fijadas por el Gobierno nacional mediante la Ley 1437 de 2014, se definió: "Artículo 102. Los recursos apropiados a la Rama Judicial para Descongestión son para cubrir dicho gasto del $1^{\circ}$ de enero hasta el 31 de diciembre del 2015 y serán ejecutados por doceavas partes incluyendo los gastos generales".

Paulatinamente se redujeron los cargos de descongestión, lo cual se llevó a cabo en dos momentos, como lo explica el presidente de la Sala Administrativa:

La Sala Administrativa del Consejo Superior de la Judicatura informa que en diciembre pasado suprimió un total de 1.813 cargos de descongestión, en dos momentos diferentes: el 19 de diciembre suprimió 993 y el 31 de diciembre los restantes 820. En total se rebajó de 7.564 a 5.751 cargos. De los cargos que se suprimieron, el 95\% se eliminó en los despachos de Tribunal y juzgados y el 5\% en las Altas Cortes [...]. El presupuesto de la rama para creación de cargos e implementación de los nuevos códigos quedó fijado en la suma de $\$ 514$ mil millones de pesos. A esa cifra hay que restarle $\$ 60$ mil millones para gastos generales, que se van para el pago de arriendo de oficinas, equipos, escritorios, sillas y demás dotaciones en las que trabajan esos cargos de descongestión. De manera que quedan $\$ 454$ mil millones de pesos, que divididos en doceavas partes da $\$ 37.8$ mil millones de pesos. Los cargos de descongestión que había hasta el 19 de diciembre pasado costaban $\$ 46.3$ mil millones al mes, lo que significa que era obligatorio, inevitable, insuperable realizar una reducción de los cargos. ${ }^{17}$

La supresión de 1.813 cargos de descongestión significa una violación inminente al principio constitucional de estabilidad laboral, que ha sido protegido por tratados internacionales y por acuerdos internacionales a los que se ha vinculado el país. La descongestión judicial ha sido concebida como una medida transitoria, razón por la cual los cargos creados para ella son de carácter provisional. Las determinaciones

16 Presidencia Consejo Superior de la Judicatura, "Razones de la disminución de algunas medidas de descongestión", http://revistacontornojudicial.com/razones-de-la-disminucion-de-algunas-medidas-de-descongestion/ (acceso agosto 30, 2015).

17 Presidencia Consejo Superior de la Judicatura, "Razones de la disminución de algunas medidas de descongestión". 
que ha tomado la Sala Administrativa del Consejo Superior de la Judicatura no han logrado cubrir las necesidades que tiene actualmente la justicia, ya que no se trata de crear juzgados y cargos para luego eliminarlos y afectar la administración de justicia.

Es un hecho indiscutible que el Gobierno nacional y el Consejo Superior de la Judicatura no han ejecutado acciones administrativas eficientes para manejar la descongestión judicial, lo que impacta negativamente en la estabilidad y los derechos laborales de los funcionarios judiciales. Varias han sido las críticas al sistema judicial, entre ellas, la del magistrado Nilson Pinilla Pinilla:

La administración de justicia, además de serle endilgadas responsabilidades de otras áreas y no contar con la colaboración ciudadana, tiene que aplicar la defectuosa legislación emanada de la correspondiente rama del poder público, al igual que decretos producidos por la ejecutiva y contar con la asistencia de ésta en muchos aspectos relacionados con su actividad, siendo por ejemplo de cargo gubernamental el sistema penitenciario y el apoyo y protección para el apropiado y seguro cumplimiento de las funciones judiciales, en lo que suelen suscitarse múltiples fallas. Desafortunadamente, no se han seguido políticas serias y estables para que exista coherencia, orden y prioridad de los intereses nacionales sobre los coyunturales y particulares, en la regulación normativa de trascendencia jurisdiccional, en alto grado caracterizada por la inestabilidad, la impulsividad circunstancial, los "bandazos" y el otorgamiento de concesiones. ${ }^{18}$

Gozar de estabilidad laboral implica tener derecho a percibir una remuneración mínima vital y móvil en proporción a la cantidad y calidad de trabajo. Los salarios actuales de los funcionarios judiciales han sido producto de las estrategias y acciones que ha llevado a cabo el sindicato que agrupa a los servidores judiciales, reconocido como Asonal.

Por medio de Asonal, los empleados del Poder Judicial lograron la promulgación de un decreto que referenciaba las mejoras en las condiciones laborales de los empleados. Se trata del Decreto 383 de 2013, que "estableció una nivelación salarial desde el año 2013 hasta el 2018”; esta bonificación judicial había sido instituida en la Ley 4 de 1992, pero solo hasta el año 2013 el Gobierno nacional expidió el Decreto que regulaba el sueldo de los funcionarios y empleados de la Rama Judicial,

18 Nilson Pinilla Pinilla, "La crisis del sistema judicial", Vniversitas, núm. 105 (2003): 381. 
como consecuencia del cese de actividades de los servidores judiciales de todo el país por más de tres meses.

Los salarios de los magistrados en las Altas Cortes han tenido paulatinos incrementos. En el año 2014, según el Decreto 194 de 2014, se mejoraron los ingresos de los magistrados:

[...] el sueldo básico de un magistrado de una alta Corte fue de \$9.175.259, adicionalmente, tendrán derecho a percibir la prima especial de servicios a que se refiere el artículo 15 de la Ley 4 de 1992 que es aquella que sumada a los demás ingresos laborales iguale a los percibidos en su totalidad por los miembros del Congreso, sin que en ningún caso los supere. La prima especial de servicios también se reconocerá cuando el empleado se encuentra disfrutando de su período de vacaciones [...] y el sueldo básico de un magistrado de Tribunal Superior es de $\$ 8.589 .956$.

Los magistrados de los Tribunales Superiores también tienen derecho a percibir una bonificación por compensación que, de acuerdo con el Decreto 1102 de 2012, es aquella que:

[... equivaldrá a un valor que sumado a la asignación básica y demás ingresos laborales iguale al ochenta por ciento (80\%) de lo que por todo concepto devenguen anualmente los Magistrados de la Corle Suprema de Justicia, Consejo de Estado, Corte Constitucional y Consejo Superior de la Judicatura.

De igual forma, tendrán derecho a la prima especial de la que trata el Artículo 14 de la Ley 4 de 1992, el cual ordena:

El Gobierno Nacional establecerá una prima no inferior al 30\% ni superior al 60\% del salario básico, sin carácter salarial para los Magistrados de todo orden de los Tribunales Superiores de Distrito Judicial y Contencioso Administrativo, Agentes del Ministerio Público delegados ante la Rama Judicial y para los Jueces de la República.

Ante los salarios de los magistrados, los salarios de los funcionarios y empleados de los juzgados del circuito y municipal son menores, según los Decretos 194 de 2014 y 383 de 2013, en los que se propone el salario del juez de circuito: "[...] es de $\$ 7.153 .213$ (más la prima especial de que trata el artículo 14 de la Ley 4 de 
1992), secretario $\$ 3.346 .772$, oficial mayor $\$ 2.883 .991$, escribiente $\$ 2.255 .623$ y el citador \$1.676.786". En el municipio, los salarios se disminuyen considerablemente: "[...] un juez municipal tiene una remuneración mensual de $\$ 5.873 .590$ (más la prima especial del artículo 14 de la Ley 4 de 1992), secretario $\$ 3.037 .813$, oficial mayor $\$ 2.518 .157$, escribiente $\$ 1.710 .000$ y citador $\$ 1.659 .367 ”$.

El régimen salarial para los magistrados de las Altas Cortes, magistrados de los Tribunales Superiores, jueces y empleados judiciales fue ampliado a los empleados y funcionarios de la Fiscalía General de la Nación, de acuerdo con el Artículo 11 de la Ley 270 de 1996:

La Rama Judicial del Poder Público está constituida por [...] 2. La Fiscalía General de la Nación, mediante el Decreto No. 019 del 2014 se le fijó el régimen salarial para dicha anualidad de la siguiente manera:

[...] Fiscal General de la Nación tiene un salario básico de $\$ 9.671 .329$, adicionalmente, tendrá derecho a la prima especial de servicios a que se refiere el artículo 15 de la Ley 4 de 1992, que sumada a los demás ingresos laborales iguales a los percibidos en su totalidad por los Miembros del Congreso, sin que en ningún caso los supere, el sueldo básico del Vicefiscal General de la Nación es de \$9.671.329 e igualmente, tendrá derecho a la prima especial de servicios a que se refiere el artículo 15 de la Ley 4 de 1992, que sumada a los demás ingresos laborales iguale a los percibidos en su totalidad por los miembros del Congreso, sin que en ningún caso los supere [...] el de un director nacional es de $\$ 14.727 .475$; jefe de departamento $\$ 5.883 .339$; fiscal delegado ante jueces municipales y promiscuos $\$ 4.600 .487$; fiscal delegado ante jueces de circuito $\$ 5.919 .805$ y asistente de fiscal I $\$ 2.032 .245$.

Los salarios de los empleados de la Rama Judicial se consideran bajos, en comparación con lo que devengan magistrados, jueces y fiscales, algunos de los cuales se encuentran entre los más altos del país, tanto en el ámbito público como en el privado. Cabe destacar que cuando se comparan los salarios del sector público con los del sector privado, estos últimos son más altos, por ejemplo, los salarios de los magistrados de las Altas Cortes son menores que los de altos ejecutivos de las empresas transnacionales o que los ingresos millonarios de las firmas de abogados reconocidos: 
[... c) El sector público no consigue establecer salarios semejantes a los observados en el sector privado por falta de recursos, restricciones políticas (la sociedad no se dispone a aceptar salarios elevados para los dirigentes públicos) o los gestores de la política salarial entienden que hay una serie de ventajas no pecuniarias para quienes actúan en el sector público, tales como una mayor estabilidad, acceso al poder e influencia, así como preferencias personales, que llevan a una persona a optar por ingresar o permanecer como dirigente en el sector público aunque el salario no sea plenamente competitivo con el pagado en el sector privado. d) Los gestores de la política salarial en el sector público no adoptan, como parámetro de determinación de los salarios para los dirigentes, las remuneraciones pagadas en el sector privado. Esta posibilidad, si fuera verdadera, perjudica sensiblemente la gestión de recursos humanos en la medida en que un mercado alternativo, o por el menos un importante parámetro de comparación para los funcionarios, no es considerado en este proceso. ${ }^{19}$

El panorama laboral de los funcionarios y empleados del sector judicial está dividido entre quienes tienen estabilidad y quienes no la tienen, debido a que la mayoría de servidores judiciales están nombrados en provisionalidad. Asimismo, no se han fijado políticas públicas efectivas para que la estructura laboral y prestacional de los servidores judiciales se adecúe a los lineamientos constitucionales e internacionales, ya que, de acuerdo con la Organización Internacional del Trabajo:

No se pondrá término a la relación de trabajo de un trabajador a menos que exista para ello una causa justificada relacionada con su capacidad o su conducta o basada en las necesidades de funcionamiento de la empresa, establecimiento o servicio. ${ }^{20}$

Al postulado de estabilidad laboral de la OIT se suma el Protocolo adicional a la Convención americana sobre derechos humanos en materia de derechos económicos, sociales y culturales, Protocolo de San Salvador. Su Artículo 7, denominado condiciones justas, equitativas y satisfactorias de trabajo, estatuyó que los Estados garantizarían en sus legislaciones laborales y de manera particular:

19 Nelson Marconi, Laura Carrillo y Claudia Helena Cavalieri, "La remuneración de los altos dirigentes del sector público. Un análisis sobre los países de América Latina", https://publications.iadb.org/handle/11319/5875?localeattribute=en (acceso octubre 20, 2015).

20 Organización Internacional del Trabajo [OIT], Convenio No. 158, sobre la terminación de la relación de trabajo (Ginebra, 22 de junio de 1982), art. 4. 
[...] d). La estabilidad de los trabajadores en sus empleos, de acuerdo con las características de las industrias y profesiones y con las causas de justa separación. En casos de despido injustificado, el trabajador tendrá derecho a una indemnización o a la readmisión en el empleo o a cualesquiera otra prestación prevista por la legislación nacional. ${ }^{21}$

Así, el derecho fundamental a la estabilidad laboral ha sido protegido por convenios internacionales y por la Constitución de 1991, pero a pesar de su avanzado reconocimiento, no se ha logrado llevar a cabo su efectiva protección. Esto trae como resultado que un sector importante de servidores judiciales se encuentre sin estabilidad laboral, debido al tipo de nombramiento previsto para los funcionarios y empleados que no son de carrera, lo cual ha sido consecuencia de las directrices administrativas que se le ha asignado a la estructura judicial desde el Consejo Superior de la Judicatura.

\section{Referencias}

Alexy, Robert. Derechos sociales y ponderación. Madrid: Fundación Coloquio Jurídico Europeo, 2009.

Ciudad Reynaud, Adolfo. "La modernización de la justicia laboral en América Latina". Revista de Derecho Procesal, núm. 3-4 (2010): 289-337.

Consejo Superior de la Judicatura. "Plan sectorial de desarrollo de la Rama Judicial 20112014". https://www.ramajudicial.gov.co/documents/10228/76250/Plan+ Sectorial+2011+-+2014.pdf/9c2ad6f7-9ce8-45f8-a281-0eb2751fle3d (acceso noviembre $25,2015)$.

Corte Constitucional. Sentencia T-406 de 5 de junio de 1992. M. P. Ciro Angarita Barón.

Ferrajoli, Luigi. Derechos y garantías. La Ley del más débil. Madrid: Trotta, 2004.

Fiscalía General de la Nación. "Fiscalía General de la Nación". http://www.fiscalia.gov.co/ colombia/wp-content/uploads/2012/03/brochure_espanol.pdf (acceso agosto 30, 2015).

García Villegas, Mauricio. "Introducción" en Jueces sin Estado. La justicia colombiana en zonas de conflicto armado, dirigido por Mauricio García Villegas, 16-17. Bogotá: Siglo del hombre editores, 2008.

21 Organización de los Estados Americanos [OEA], Protocolo adicional a la Convención americana sobre derechos humanos. Protocolo de San Salvador (San Salvador, 17 de noviembre de 1988), art. 7. 
Kelsen, Hans. La garantía jurisdiccional de la Constitución. La justicia constitucional. México D. F.: Instituto de investigaciones jurídicas, 2001.

Marconi, Nelson, Laura Carrillo y Claudia Helena Cavalieri. "La remuneración de los altos dirigentes del sector público. Un análisis sobre los países de América Latina”. https:// publications.iadb.org/handle/11319/5875?locale-attribute=en (acceso octubre 20, 2015).

Organización de los Estados Americanos [OEA]. Protocolo adicional a la Convención americana sobre derechos humanos. Protocolo de San Salvador. San Salvador, 17 de noviembre de 1988.

Organización Internacional del Trabajo [OIT]. Convenio No. 158, sobre la terminación de la relación de trabajo. Ginebra, 22 de junio de 1982.

Pinilla Pinilla, Nilson. "La crisis del sistema judicial". Vniversitas, núm. 105 (2003): 375-414.

Presidencia Consejo Superior de la Judicatura. "Razones de la disminución de algunas medidas de descongestión". http://revistacontornojudicial.com/razones-de-la-disminucion-dealgunas-medidas-de-descongestion/ (acceso agosto 30, 2015).

Rama Judicial. "Estructura y funciones de la administración de justicia". http://www. ramajudicial.gov.co/documents/10228/1468683/estructura+y+funciones+de+la+ad ministracion+de+la+justicia.pdf/d016a449-f9c7-44ed-blfc-fbdac24b6575 (acceso noviembre 22, 2015).

Silva García, Germán. El mundo real de los abogados y de la justicia. La profesión jurídica. Tomo I. Bogotá: Universidad Externado de Colombia, ILSA, 2001.

Silva García, Germán. El mundo real de los abogados y de la justicia. Administración de justicia. Tomo III. Bogotá: Universidad Externado de Colombia, ILSA, 2001. 